\title{
FACING SMART-WISE ENCOUNTERS IN FL EDUCATION
}

\author{
Kamilya Karabayeva \\ Asst. Prof. Dr. Linguistic Center (Almaty Management University), KAZAKHSTAN \\ kamilya0705@gmail.com
}

\begin{abstract}
This article reveals the great potential of technology for bilingual language learners in foreign languageblended education.

The world of education has undergone great changes due to the pandemic, in turn leading to a great deal of change in foreign language education. This is reflected in global online education and it sets the rules for both teachers and learners to follow. Yet where online education is applied haphazardly merely as a reaction to our changing world, its fast-growing methods and techniques then undoubtedly lead to ambiguity and disarray in the FL classroom.

Our study is aimed at showing the great potential and didactical value of modern technology when combined with the help of the professional communicative competence as an educational outcome in a foreign language-blended classroom.

The theoretical framework of our study includes cognitive as well as reflective concepts.

The methodological framework is reflected in the experimental study that involved 54 undergraduates and second-year students who were taught over a period of four months with new technologies including Microsoft teams, Zoom, Google meet, Google forms, Moodle, Padlet, Portfolio, etc. in a foreign languageblended classroom.

Educational outcome is determined by the formation of professional communicative competence (with a set of sub-competences) with the help of Microsoft teams, Zoom, Google meet, Google forms, Moodle, Padlet, Portfolio, etc.

The didactical value of the aforementioned technologies has been proven to be effective and motivating, and is furthermore discussed in the "Discussion and Conclusion" section.
\end{abstract}

This article is of topical interest to educators, learners, teachers and researchers.

Keywords: competences, technologies, blended education, methods, techniques.

\section{INTRODUCTION}

Globalization dictates that education should take priority in the social sphere of human society. Being an educated person is integral to everyone's self-development and self-knowledge, and key to one's successful future, as well as to the welfare of a country and society as a whole. The Kazakhstani educational system 
has been dynamically adapting to the changing conditions of the educational process, and is now occupying its niche in the global community as it joined the Bologna Process in 2010. This has conditioned the development of new approaches to education and research, which are detailed in the proceedings of the prominent Kazakhstani and foreign researchers. Not knowledge but competencies should be seen as the education learning outcome. The core values of Education of the Future will include willingness and ability to solve problems, navigate the infinite torrents of information looking for correct answers and choosing lifeproposed alternatives, develop inherent individual abilities of each person, show genuine interest in one's favorite occupation, in the latest best practices in research. All this presumes an educational paradigm shift.

Education is a permanent task-oriented and controlled process regulated within the system and timelines and is absolutely necessary for fulfilling a human potential of self-improvement and transformation of nature and the world around man.

Today, a new generation of teachers is needed, who would be able and willing to adapt easily to this rapidly changing innovative educational environment. For this, they should possess such professional qualities that a teacher of the future would require to promote the digitalization of the national education system. Today, a new generation of teachers is needed, who would be able and willing to adapt easily to this rapidly changing innovative educational environment. For this, they should possess such professional qualities that a teacher of the future would require to promote the digitalization of the national education system.

\section{RESEARCH OBJECTIVES}

1) To develop a model for the formation of professional communicative competence combined with linguoprofessional, pragmatic, discursive, strategic and communicative sub-competencies, reveal its criterion-featured aspects.

2) To develop a rationale of the cognitive-reflexive-axiological approach as a conceptual methodological basis for professional-based communication.

3) To substantiate the didactic potential of the digital technologies and tools as an integral mechanism for the formation of IT-based professional communicative competence.

4) To create an integrated information and learning environment on the "Microsoft teams" platform didactically governing the formation of professional communicative competence.

\section{RESEARCH AIM}

to substantiate and collaborate a conceptual basis and methodology for the phased formation of professional communicative competence as a methodological category-specific of an IT-based foreign language school.

\section{RESEARCH METHODS}

study and critical analysis of the relevant research works; modeling; targeted observation and analysis of the educational process; testing; teaching during testing and experimental process.

\section{THEORETICAL FRAMEWORK}

The cognitive-reflexive-axiological approach in the English language learning is based on the consciousness of the definite linguistic cognitive system. Scientists claim that «the cognitive process of language acquisition - is the representation of the mental acquisition device in accordance with the principles of language knowledge perception that made the speech production more vivid and comprehensive [7, p. 201].

The cognitive approach as the part of the cognitive-reflexive-axiological approach "teaches language as the form of self-expression. Though the cognitive-communicative approach is aimed at the concept of «teaching language as a self-expression, as the mean of the communication within multicultural community in order to teach learner not only different language but different culture» [15, p. 36].

Learning language in the process of foreign language education is seen as a foreign language culture. From the different angle the communication among people happens only with the aim of cognition, obtaining new knowledge about the reality and transmitting it from generation to generation» [12, p. 58].

Speaking about the reflexive approach in a foreign language as the part of the cognitive-reflexive-axiological approach, «reflexive aspect is the basis for the successful educational as well as professional activity within all the structural components of the professional competence» [10, p. 34].

Pedagogical reflexive notion is meant as continuous «action on self-analysis in the professional based 
community among communicators for the sake of the analysis and further modification of the professional communicator» [13, p. 66].

It is necessary to analyze the situation because of the obsolescence of knowledge as well as obsolescence of pedagogical strategies and techniques. The teacher's aim is to monitor such phenomena with the help of reflexive mechanisms and update them. It is necessary to carry out the fact that the pedagogical reflexive method is the most actual method of the post-soviet environment [2, 9].

Pedagogical reflexive method is of great importance in the Foreign language education [4]. The reason of reflexive method actuality is because during many years, over a long period of time, the was only conservative system of education that contradicts with the needs of the modern multicultural society [1].

Therefore the meaning of the pedagogical reflexive method in a foreign language education is of acute need. In particularly of social situation, modern teacher of foreign language is regarded as researcher as well as practitioner. The mission of such a teacher is not only scientific development of the pedagogical strategies, but implementation of them in a rapidly changes of the multicultural society among students with different ethical and spiritual values, mental capabilities [6].

Understanding of such peculiarities allow a FL University teacher create learning environment for the formation of the communicative competence because «productive cross-cultural communication cannot arise by itself, it is need purposefully learn» [5]. For students with multicultural background and ethnicity it is easier to create adequate intercultural communication, then apply different pedagogical reflexive strategies in order to check their improvements in a foreign language proficiency level.

The third method is axiological which includes the value paradigm of the contemporary society. Axiological approach is one of the most vast humanistic approach with rich traditions of a philosophical thought [14, p. 109]. If cognitive and reflexive approaches are oriented primarily at the practical implementation education, but axiological to a greater extend is a theoretical model. That is determined by peculiar feature of such a phenomenon in a human society as "value" [11, p. 57].

Axiological approach in a Foreign language education has two meanings, first is seen by the teacher's system of value, second, it is seen by student' system of value. By the way, there are exist different methods that allow to form professional value attitude of teachers towards their profession [3], and also axiological systems of education such the system of a foreign language education [8]. One of the important aspect of axiological system in the teaching practice is historically introduced picture of the moral high ground of the teacher his professional values. System of values of the teacher influences on the development of the system of values of the students, next generation.

It is seen obvious interaction of cognitive and reflective approaches because these approaches allow to solve the cognitive, practical goals of the education. But the axiological approach represents mainly strategic and valuable asset and is a solid conceptual background for the cognitive as well as reflective approaches. That is resulted into new pedagogical paradigm.

In our scientific research we define newly brand conceptual integrated approach as cognitive-reflexiveaxiological approach.

Cognitive-reflexive-axiological approach has been developed as a conceptual framework for professional communication, which is aimed at producing learning outcome "intermediator of professional communication" possessing tactics and strategies of intercultural communication in an digital environment.

\section{RESEARCH DESIGN}

The research was conducted in Almaty Management University and lasted for four months. The research was conducted in three stages. In the first stage, the theoretical framework for the research was established and existing literature on the problem of the development of professional communicative competence was analyzed.

In the second stage, the methodological model of the development of professional communicative competence was worked out, incorporating digital technologies.

At the third stage, experimental work was included to check the effectiveness of the methodology of the development of professional communicative competence with the implementation of digital technologies.

\section{RESEARCH PARTICIPANTS}

The participants were 54 students of Almaty Management University, all studying English for Academic 
Purposes (EAP). The age range was 19-20 years old. In the course of the study, all research participants were assigned to two groups: experimental and control. In the experimental group, there were 27 students and in the control group 27. The selection of second-year students as participants was conditioned by the required level of the students' level of proficiency in the conditions of the competence approach based on the professional model of the specialist.

\section{RESEARCH PROCEDURES}

The experiment was conducted with two groups of EAP students. One of the groups was the experimental group (EG) the second group was the control group (CG). In CG the classes were conducted according to the regular EAP syllabus. In the EG, in addition to the regular EAP syllabus, digital technologies were implemented. In each group, the lessons were conducted once a week. The classes with the EG were conducted on the Microsoft platform. The classes with the CG were conducted in a regular classroom not equipped with ICT. To listen to the audio files that were indicated in the EAP coursebook the researcher also used her own laptop in the CG.

The classes in the CG were conducted by the researcher with the use of the EAP coursebook. In the EG the researcher taught the same EAP content as in the CG but with the help of digital technologies. The digital technologies implemented during the experiment included: Microsoft teams, Zoom, Google meet, Google forms, Moodle, Padlet, Portfolio, etc.

The research led to the creation of an electronic class with the help of the Microsoft teams, Zoom, Google meet, Google forms, Moodle, Padlet, Portfolio, etc. were used for the presentation of the schedule of the course oral and written assignments, distance communication between the research participants and the researcher, and feedback on the classes and assignments from the participants. In addition, it allowed the researcher to send personal comments to the participants and give feedback on the latters' comments.

A portfolio was used for the collection of students' reflections on class assignments, learning students' opinions about different assigned topics. These assignments were emailed to the researcher on a regular basis.

"Audio recordings" were implemented for the development of students' speaking skills. It was used to afford the research participants the opportunity to record their speech, with the opportunity of further listening to it so that the students could analyze their progress by themselves. Students' recordings were also sent to the researcher so that she could check the students' progress and at the same time save classroom time owing to the possibility of simultaneous participation including all the students on one and the same task without disturbing each other's performance.

The experiment was structured in the following way: 1) Diagnostics. At this stage the pre-test was conducted to check the level of development of the professional communicative competence in EG and CG; 2) experiment. During this stage in EG, digital technologies were implemented; 3) Analytics. Here the post-test was conducted in EG and CG to check if the implementation of digital technologies in the process of EAP teaching made a difference in the level of development of the professional communicative competence in comparison to the teaching given according to a standard EAP syllabus without the use of the digital technologies.

\section{DATA COLLECTION}

Before conducting the experiment, both groups were asked to complete a pre-test to reveal their level of proficiency as well as the development of professional communicative competence in EG and CG. This pretest contained five sections. Each section included the task of checking the level of development of each of the sub-competences, such as: linguoprofessional, pragmatic, discursive, strategic and communicative subcompetencies which constitute the professional communicative competence.

After conducting a number of classes in EG with the use of digital technologies, and in CG without it, students of both groups were asked to complete the post-test to check their progress in the development of their professional communicative competence. The structure of the post-test was the same as the structure of the pre-test and consisted of five tasks where each task was aimed at measuring the development of a particular sub-competence.

\section{DATA ANALYSIS}

The research data was analyzed by means of calculating and comparing the results of the pre- and post-test in EG and CG. First of all the average results of the pre- and post-tests were calculated for every sub- 
competence in the EG and CG. After that, the total score was calculated for the pre- and post-tests for EG and CG. Finally, the pre- and post-test results of EG and CG were compared.

The average grade was calculated according to the following formula: $\mathbf{C a}=\sum \mathbf{n} 1 / \mathbf{N}$; where:

Ca - stands for the coefficient of the development of the professional communicative abilities;

$\sum \mathrm{n} 1$ - stands for the sum of the received points; and $\mathbf{N}$ - stands for the number of participants.

\section{RESEARCH RESULT}

The pre-test and post-test results for the EG are presented in Table 1. In this table, there are the results achieved by the research participants during the pre- and post-tests according to the level of development of each sub-competence, and the total score for the level of development of the professional communicative competence.

Table 1. The pre- and post-test results of the EG

\begin{tabular}{|c|c|c|c|c|}
\hline $\begin{array}{l}\text { Subcompetenc } \\
\text { e }\end{array}$ & Criteria & $\begin{array}{l}\text { Point } \\
\text { s }\end{array}$ & $\begin{array}{l}\text { Pre- } \\
\text { Test } \\
\text { Result } \\
\text { s }\end{array}$ & $\begin{array}{l}\text { Post- } \\
\text { Test } \\
\text { Results }\end{array}$ \\
\hline 1 & 2 & 3 & 4 & 5 \\
\hline $\begin{array}{l}\text { Linguoprofession } \\
\text { al }\end{array}$ & $\begin{array}{l}\text { - Information component } \\
\text { - Linguistic component }\end{array}$ & 20 & 16,4 & 18,2 \\
\hline Pragmatic & $\begin{array}{l}\text { - Information component } \\
\text { - Linguistic component } \\
\text { - Logical-compositional } \\
\text { component }\end{array}$ & 20 & 14,1 & 15,7 \\
\hline Discursive & $\begin{array}{l}\text { - Information component } \\
\text { - Logical-compositional } \\
\text { component } \\
\text { - Argumentative } \\
\text { component }\end{array}$ & 20 & 17,2 & 17,7 \\
\hline Strategic & $\begin{array}{l}\text { - Information component } \\
\text { - Cultural component } \\
\text { - Linguistic component }\end{array}$ & 20 & 12,7 & 15,4 \\
\hline Communicative & $\begin{array}{l}\text { - Sociocultural } \\
\text { component } \\
\text { - Linguistic component } \\
\text { - Argumentative } \\
\text { component }\end{array}$ & 20 & 17,6 & 18,5 \\
\hline \multicolumn{2}{|l|}{ Total score: } & 100 & 78,0 & 85,5 \\
\hline
\end{tabular}

In Table 2 there are the results of the pre- and post-tests for the CG. The results of the pre-test indicate that EG and CG initially have approximately the same level of development of professional communicative competence. Though the CG showed a slightly lower score from the very beginning, the results of the posttest indicate that the EG increased its score in comparison to the pre-test by 7.5 points and in comparison with the final results of the CG by 6.8 points. The CG also increased its score in the post-test in comparison to the pre-test by 2.7 points. However, the CG lost 0.1 point in the pragmatic sub-competence. 
Table 2. The results of the pre-test and post-test of the CG

\begin{tabular}{|c|c|c|c|c|}
\hline Subcompetence & Criteria & $\begin{array}{l}\text { Point } \\
\text { s }\end{array}$ & $\begin{array}{l}\text { Pre- } \\
\text { Test } \\
\text { Result } \\
\text { s }\end{array}$ & $\begin{array}{l}\text { Post- } \\
\text { Test } \\
\text { Result } \\
\text { s }\end{array}$ \\
\hline 1 & 2 & 3 & 4 & 5 \\
\hline $\begin{array}{l}\text { Linguoprofession } \\
\text { al }\end{array}$ & $\begin{array}{l}\text { - Information } \\
\text { component } \\
\text { - Linguistic component }\end{array}$ & 20 & 15,6 & 16,2 \\
\hline Pragmatic & $\begin{array}{l}\text { - Information } \\
\text { component } \\
\text { - Linguistic component } \\
\text { - Logical-compositional } \\
\text { component }\end{array}$ & 20 & 15,1 & 15,0 \\
\hline Discursive & $\begin{array}{l}\text { - Information } \\
\text { component } \\
\text { - Logical-compositional } \\
\text { component } \\
\text { - Argumentative } \\
\text { component }\end{array}$ & 20 & 16,2 & 16,6 \\
\hline Strategic & $\begin{array}{l}\text { - Information } \\
\text { component } \\
\text { - } \quad \text { Cultural component } \\
\text { - Linguistic component }\end{array}$ & 20 & 12,3 & 13,7 \\
\hline Communicative & $\begin{array}{l}\text { - Sociocultural } \\
\text { component } \\
\text { - Linguistic component } \\
\text { - Argumentative } \\
\text { component }\end{array}$ & 20 & 16,8 & 17,2 \\
\hline \multicolumn{2}{|l|}{ Total score: } & 100 & 76,0 & 78,7 \\
\hline
\end{tabular}

\section{INTERPRETATION OF THE RESEARCH RESULTS}

Analysis of the results has shown that the EG achieved better results in the post-test in comparison to the CG. The difference in the final score is 6.8 points. Such a difference confirms the hypothesis of the current study that the implementation of digital technologies into foreign language education facilitates the development of professional-communicative competence. The results of the CG show that the currently existing foreign language teaching methodology also develops the professional communicative competence, but it would be more effective if foreign language teaching involved Digital technologies such as: Microsoft teams, Zoom, Google meet, Google forms, Moodle, Padlet, Portfolio, etc.

\section{DISCUSSION AND CONCLUSIONS}

The results of the current study prove that the implem entation of digital technologies into the foreign language education system leads to more effective development of professional communicative competence in comparison to teaching according to a standard program. This could be explained by the possibilities that are provided by the implementation of digital technologies into the foreign language education. 
Digital technologies allow access to sources of authentic information, removes geographical boundaries, encourages learners' motivation for self-development, creates opportunities for self-evaluation, and imposes on students a responsibility for their own learning. Though current research confirms the research hypothesis, its results are in no way conclusive and there is a need for further investigation in the area because of the number of limitations to this research.

Among such limitations is the limit on time. Most probably, research lasting longer would show a more distinct influence of digital technologies on the development of professional communicative competence. Another limitation of the current study was the small number of research participants, which is why the results of the study do not allow us to make any statistically significant claims.

Considering the limitations of the current study we suggest that future research into the use of digital technologies in foreign language teaching be conducted with a larger amount of participants, and for a longer period of time. As for possible research topics in this area, we could advise study of the influence of every technology implemented in the currently ongoing study of the development of the professional communicative competence, to find out which of the implemented technologies Microsoft teams, Zoom, Google meet, Google forms, Moodle, Padlet, Portfolio, etc. are the most effective. This, as well as comparing the effect of the aforementioned technologies on every separate sub-competence.

Summing up, the implementation of digital technologies into foreign language training leads to progress in the development of professional communicative competence and allows us to become competent participants in the global labor market. Thus, the use of digital technologies is a step forward in foreign language education and the development of specialists of the new formation who meet the demands of the global community. However, the issue of digital technologies in foreign language education needs further research.

\section{REFERENCE LIST}

1. Ashby, P., Hobson, A., Tracey, L., Malderez, A., Tomlinson, P., Roper, T., Chambers, G., Healy, J. (2008). Beginner teachers experiences of initial teacher preparation, induction and early professional development: a review of literature. London: DCSF.

2. Barysheva, T. D. (2011). The reflexive approach in the development of the professional consciousness and self-consciousness of future teachers within the modernization of the high school. Vector science of the Togliatti State University. Series: Pedagogy, phycology, 3 (6). Wong, H. (2004). Induction programs that keep new teachers teaching and improving. NASSP Bulletin, 88 (638).

3. Dolgushina, N. A., Chizhakova G. I. (2011). Axiological focus of professional training of future bachelors within professional education: theory and practice. Bulletin of Krasnoyarsk State Pedagogical University named after V. P. Astafiev, 4 (18).

4. Green, E. (2015). Building a Better Teacher: How Teaching Works (and How to Teach It to Everyone). New York: W. W. Norton \& Company Incorporated.

5. Grushevitskaya, T. G., Popkov, V. D., Sadokhin, A. P. (2002). Basics of intercultural communication. Moscow: UNITY-DANA.

6. Jabbar, A., Hardaker, G. (2013). The role of culturally responsive teaching for supporting ethnic diversity in British University Business Schools. Teaching in Higher Education. 18 (3).

7. Karabutova, E. A. (2013). Modern methodological concepts of students' education within professional communication in a foreign language. Proceedings of Voronezh State University. Series "Linguistics and Intercultural Communication", 1.

8. Kiryakova, A. V., Olkhovaya, T. A. (2010). Realization of the axiological approach in the university education. Higher education in Russia, 5.

9. Kokolova, T. V. (2013). Modern approaches in the pedagogical practices of future pedagoguespsychologists: reflexive technologies. “The World of Science, Culture. Education”, № 1 (38).

10. Maximov, A. N. (2010). Formation of the reflexive competence in the preparation process of physical 
training teachers. Bulletin of Novgorod State University, 58.

11. Purgina, E. I. (2011). Axiological aspect of modern education and philosophical teaching about values by S. I. Gessen. "Pedagogical Education in Russia", 1.

12. Troyanova, I. M. (2008). Cognitive function as one of the most important language functions. Tomsk State Pedagogical University Bulletin, 76 (2).

13. Usheva, T. F. (2014). Reflexive approach implementation in a pedagogical education. "Siberian pedagogical journal", 5 .

14. Yershov, V. L. (2011). Philosophical basics of the axiological approach in education. Vestnik of NorthEastern Federal University named after M. K. Ammossov. Series "Pedagogics. Psychology. Philosophy", 3.

15. Yussupova, T. G. (2014). The meaning of Cognitive-communicative approach in foreign language study. Bulletin of Kostroma State University named after N. A. Nekrassov. Series "Pedagogy. Psychology Social work. Juvenology. Sociokinetics", 4. 